\title{
A SHORT-TERM STUDY OF THE SAFETY, PHARMACOKINETICS, AND EFFICACY OF RITONAVIR, AN INHIBITOR OF HIV-1 PROTEASE
}

\author{
Sven A. Danner, M.D., Andrew Carr, M.D., John M. Leonard, M.D., Leah M. Lehman, Ph.D., \\ Francesc Gudiol, M.D., Juan Gonzales, M.D., Antonio Raventos, M.D., Rafael Rubio, M.D., \\ Emilio Bouza, M.D., Vicente Pintado, M.D., Antonio Gil Aguado, M.D., Juan Garcia de lomas, M.D., \\ Rafael Delgado, M.D., Jan G.C. Borleffs, M.D., Ann Hsu, Ph.D., JoaQuin M. Valdes, M.D., \\ Gharles A.B. Boucher, M.D., and David A. Cooper, M.D., for the European-Australian \\ Collaborative Ritonavir Study Group*
}

\begin{abstract}
Background. Reverse-transcriptase inhibitors have only moderate clinical efficacy against the human immunodeficiency virus type 1 (HIV-1). Ritonavir is an inhibitor of HIV-1 protease with potent in vitro anti-HIV properties and good oral bioavailability.

Methods. We evaluated the antiviral activity and safety of ritonavir in a double-blind, randomized, placebocontrolled phase 1 and 2 study of 84 HIV-positive patients with 50 or more CD4+ lymphocytes per cubic millimeter. The patients were randomly assigned to one of four regimens of ritonavir therapy, or to placebo for four weeks and then (by random assignment) to one of the ritonavir regimens.

Results. During the first 4 weeks, increases in CD4+ lymphocyte counts and reductions in the log number of copies of HIV-1 RNA per milliliter of plasma were similar among the four dosage groups, but in the three lowerdosage groups there was a return to base-line levels by 16 weeks. After 32 weeks, in the seven patients in the
\end{abstract}

$\mathrm{T}$ HE clinical use of nucleoside-analogue inhibitors of reverse transcriptase is limited by toxic effects and the emergence of mutants of the human immunodeficiency virus (HIV) that resist these drugs. ${ }^{1}$ HIV type 1 (HIV-1) protease cleaves the viral Gag-Pol polyprotein precursor into the Gag proteins and the enzymes integrase and protease. If the Gag-Pol precursor molecule is not processed in this way, noninfectious particles are formed. ${ }^{2}$ Inhibition of HIV-1 protease therefore represents an attractive alternative strategy to the inhibition of reverse transcriptase in the treatment of HIV-1 infection. ${ }^{3}$

The identification of protease inhibitors with antiretroviral activity in vivo has been hampered by the poor oral bioavailability of many molecules in this class. The large size of many of these agents makes their absorption difficult, and they may be rapidly cleared from plasma, as has been noted with two of the first protease in-

From the Academic Medical Center, Amsterdam (S.A.D., C.A.B.B.); St. Vincent's Hospital, Sydney, Australia (A.C., D.A.C.); Abbott Laboratories, Abbott Park, Ill. (J.M.L., L.M.L., A.H., J.M.V.); the Hospital de Bellvitge "Principes de España," Barcelona, Spain (F.G.); the Hospital La Paz, Madrid (J.G., A.G.A.); the Hospital Germans Trias i Pujol, Barcelona, Spain (A.R.); the Hospital 12 de Octubre, Madrid (R.R., R.D.); the Hospital General Gregorio Marañon, Madrid (E.B.); the Hospital Ramón y Cajal, Madrid (V.P.); the Hospital Clinico de Valencia, Valencia, Spain (J.G.L.); and the University Hospital Utrecht, Utrecht, the Netherlands (J.C.C.B.). Address reprint requests to Dr. Danner at the Division of Infectious Diseases, Tropical Medicine, and AIDS, Academic Medical Center, University of Amsterdam, Meibergdreef 9, 1105 AZ Amsterdam, the Netherlands.

Supported by Abbott Laboratories.

*The other institutions and investigators participating in the European-Australian Collaborative Ritonavir Study Group are listed in the Appendix. highest-dosage group (600 $\mathrm{mg}$ of ritonavir every 12 hours), the median increase from base line in the CD4+lymphocyte count was 230 cells per cubic millimeter, and the mean decrease in the plasma concentration of HIV-1 RNA (as measured by a branched-chain DNA assay) was 0.81 log (95 percent confidence interval, 0.40 to 1.22). In a subgroup of 17 patients in the two higher-dosage groups, RNA was also measured with an assay based on the polymerase chain reaction, and after eight weeks of treatment there was a mean maximal decrease in viral RNA of $1.94 \log$ (95 percent confidence interval, 1.37 to 2.51). Adverse events included nausea, circumoral paresthesia, elevated hepatic aminotransferase levels, and elevated triglyceride levels. Ten withdrawals from the study were judged to be related to ritonavir treatment.

Conclusions. In this short-term study, ritonavir was well tolerated and had potent activity against HIV-1, but its clinical benefits remain to be established. ( $\mathrm{N}$ Engl J Med 1995;333:1528-33.)

hibitors studied in humans, A-77003 and saquinavir., ${ }^{4,5}$ Ritonavir is a novel inhibitor of HIV-1 protease that has good oral bioavailability in dogs and monkeys (90 and 70 percent, respectively; unpublished data). It has potent antiretroviral activity and reached high plasma concentrations safely in phase 1 clinical trials. ${ }^{6}$ Its prolonged absorption phase and half-life of three to four hours permitted the use of a twice-daily dosing schedule to achieve adequate drug levels.

\section{MethodS}

The study was designed as a multicenter (10-site), double-blind, placebo-controlled study. A four-week, placebo-controlled phase was followed by a maintenance phase in which the patients continued ritonavir therapy. For patients receiving antiretroviral therapy at study entry, there was a two-week washout period before randomization. Patients assigned to group 1 were randomly assigned to receive twicedaily doses of $300 \mathrm{mg}$ of ritonavir, $400 \mathrm{mg}$ of ritonavir, or matching placebo. After the enrollment in group 1 had been completed and half of those patients had been treated for at least two weeks without serious toxic effects, patients were assigned to group 2 and were randomly assigned to receive twice-daily doses of $500 \mathrm{mg}$ of ritonavir, $600 \mathrm{mg}$ of ritonavir, or matching placebo. Thereafter, all the patients were allowed to continue into the maintenance phase. During that phase, patients who had initially been given placebo were again randomly assigned, in a double-blind manner, to one of the two ritonavir dosages used in their treatment group.

The principal criteria for inclusion in the study were as follows: age of 18 years or older, documented HIV-1 infection, a CD4+ lymphocyte count greater than 50 cells per cubic millimeter as measured twice during a three-week screening period (before the washout period), and a plasma concentration of HIV p24 antigen of $10 \mathrm{pg}$ per milliliter or higher. Patients were required never to have been treated with any HIV-1 protease inhibitor, and they had to have Karnofsky performance scores of 70 or higher. Women could participate in the 
study if they were not of child-bearing potential. All the patients gave written informed consent.

Indicators of treatment efficacy included the $\mathrm{CD} 4+$ lymphocyte count and the plasma concentrations of HIV-1 p24 antigen and viral RNA. CD4+ lymphocytes were measured by two-color flow cytometry, p24 antigen with a commercially available kit (Abbott), and RNA with a branched-chain DNA assay (Chiron) that had a lower limit of detection of 10,000 RNA equivalents per milliliter. ${ }^{7}$ In a subgroup of 17 patients, levels of viral RNA were also measured by a more sensitive prototypic quantitative polymerase-chain-reaction (PCR) assay (Roche Molecular Systems). ${ }^{8}$ Ritonavir levels were assessed by reverse highperformance liquid chromatography, as described elsewhere. ${ }^{6}$ To monitor trough concentrations of ritonavir, blood samples were drawn after three and seven days of treatment and after two, three, and four weeks. At the end of the third week, serial blood samples were collected over an eight-hour period to determine drug levels. The protocol was approved by the institutional review board at each participating center.

\section{Statistical Analysis}

The statistical analyses were performed with SAS software (version 6.07). Demographic characteristics were compared by either Fisher's exact test or one-way analysis of variance. Base-line immunologic and virologic measures were compared between dosage subgroups by the Kruskal-Wallis test and a one-way analysis of variance, respectively. Mean and median changes from base line in measures of efficacy were compared by the t-test and the Wilcoxon rank-sum test, respectively. Mean changes from base line in selected measures pertaining to drug safety were compared by a one-way analysis of variance.

Pharmacokinetic measures were obtained by standard noncompartment methods. These measures included the maximal concentration of ritonavir; the time required to attain the maximal concentration in an eight-hour period; the area under the curve for the plasma concentration of ritonavir plotted against time (as computed with linear trapezoidal rules); the degree of fluctuation in the area under the curve (calculated by subtracting the trough concentration from the maximal concentration and dividing the difference by the average concentration, defined as the area under the curve for an eight-hour period divided by 8); the trough concentration of ritonavir; the rate of apparent clearance of ritonavir (calculated by dividing the ritonavir dose by the area under the curve estimated for a 12-hour period with the concentration during hour 12 by log-linear extrapolation); and the halflife of ritonavir, which was calculated as the natural log of 2 divided by the rate of disappearance of ritonavir from plasma between hour 6 and hour 8.

\section{Results}

\section{Four-Week, Placebo-Controlled Phase}

Eighty-four patients entered the study, 39 in group 1 and 45 in group 2. Their demographic characteristics, risk factors for HIV infection, body weight, and Karnofsky performance scores were similar across all six treatment subgroups. All but three participants were male.

Measures of efficacy obtained at base line and a summary of the previous use of antiretroviral agents in each subgroup are shown in Table 1 . When base-line measures of efficacy were compared, there were no statistically significant differences among subgroups except in the CD4+ lymphocyte counts in group 2: these counts were lowest in the placebo subgroup and highest in the subgroup receiving $500 \mathrm{mg}$ of ritonavir every 12 hours $(\mathrm{P}=0.033)$. The proportion of patients who used antiretroviral therapy during the three months before the administration of the study drug was similar in all treatment subgroups, ranging from 60 to 85 percent.

\section{Measures of Efficacy}

The mean change in log concentrations of HIV-1 RNA, the median change in GD4+ lymphocyte counts, and the median change in concentrations of HIV p24 antigen as compared with the base-line values are shown in Figure 1. There were significant decreases in viral RNA and p24 antigen at one week that were sustained through week 4 in all four ritonavir subgroups $(\mathrm{P}<0.01$ for the comparison with the placebo subgroups for both measures at all measurements). After two weeks of treatment, increased CD4+ lymphocyte counts were observed in the subgroups receiving 400, 500 , and $600 \mathrm{mg}$ of ritonavir every 12 hours; these increased counts continued through week 4 and were significantly higher at all measurements than those in the placebo subgroups $(\mathrm{P}<0.05)$. Increased counts were also found among the patients with low CD4+ counts at base line: among 29 patients with base-line CD4+ lymphocyte counts below 100 cells per cubic millimeter, 22 had maximal increases of more than 100 cells per cubic millimeter, and 8 of these had increases of at least 200 cells per cubic millimeter.

\section{Pharmacokinetic Measures}

Table 2 summarizes the pharmacokinetic measures obtained after three weeks. Plasma concentrations of ritonavir were higher with larger doses, with the mean apparent clearance of the drug at day 21 remaining relatively constant among dosage subgroups. The plasma concentrations remained higher than $2.1 \mu \mathrm{g}$ of ritonavir per milliliter, the concentration estimated in vitro to be 90 percent effective after adjustment for binding to human plasma proteins, at almost all meas- 
urements made in patients receiving $400 \mathrm{mg}$ or more of ritonavir every 12 hours. The ratio of the maximal concentration to the trough concentration ranged from approximately 4.6 in the subgroup receiving $300 \mathrm{mg}$ every 12 hours to approximately 3.8 in the three sub-
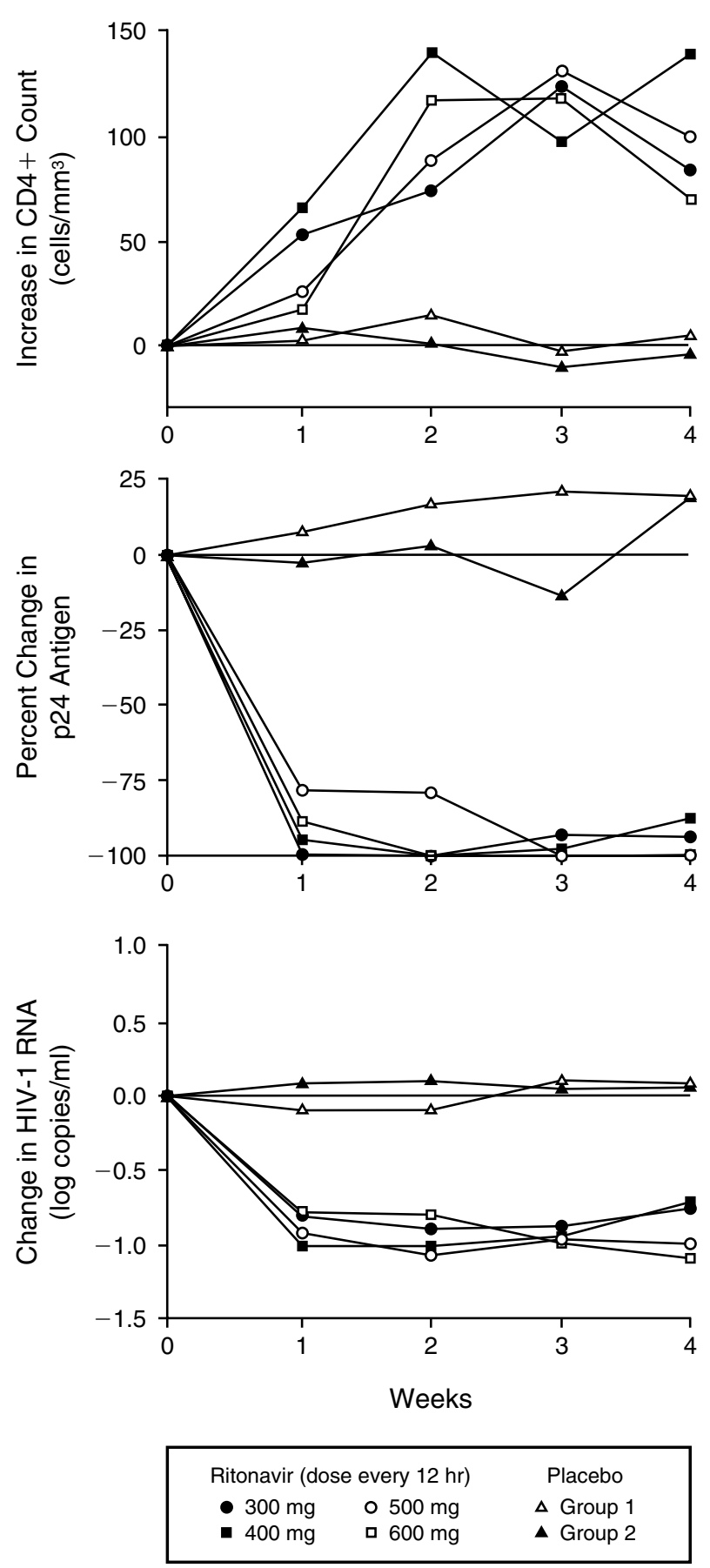

Figure 1. Immunologic and Virologic Measures during the FourWeek, Placebo-Controlled Phase, According to Dosage Subgroup.

The top panel shows the median changes from base line in the absolute CD4+ cell count, the middle panel the median percentages of change from base line in the plasma concentration of HIV-1 p24 antigen, and the bottom panel the mean changes in the log number of copies of HIV-1 RNA, as measured by the branched-DNA technique. groups receiving higher dosages, with fluctuations over an 8-hour period that averaged less than 1.3 for all four subgroups.

\section{Maintenance Phase}

Seventy-six of the 84 patients who participated in the initial four-week, placebo-controlled phase continued ritonavir treatment or began such treatment in the maintenance phase. The data reported here are summarized according to the patients' cumulative exposure to ritonavir. Demographic characteristics, base-line Karnofsky scores, and base-line measures of efficacy were similar among all ritonavir subgroups during the maintenance phase. Results are presented for up to 32 weeks of treatment with ritonavir.

\section{Measures of Efficacy}

The median change from base line in the CD4+ lymphocyte count and the mean change in the log concentration of HIV-1 RNA are shown in Figure 2. There were mean decreases of $0.78,0.83,0.97$, and $1.13 \mathrm{log}$ per milliliter of plasma in the concentration of viral RNA at week 4 in the subgroups receiving 300, 400, 500, and $600 \mathrm{mg}$ of ritonavir every 12 hours, respectively. After 16 weeks of treatment with ritonavir, the mean concentrations of viral RNA in the 300-mg and 400-mg subgroups approached the base-line values once again; there were no significant differences between the values obtained in these subgroups at any point during the 32 weeks of treatment. Treatment with 500 or $600 \mathrm{mg}$ of ritonavir every 12 hours produced more lasting effects on concentrations of viral RNA. After 20 weeks of ritonavir treatment, the mean reduction in HIV-1 RNA in the subgroup receiving $500 \mathrm{mg}$ every 12 hours became smaller, whereas the size of the reduction was sustained in the subgroup receiving $600 \mathrm{mg}$ every 12 hours. There was a statistically significant difference in concentrations of viral RNA between these two subgroups at 32 weeks $(\mathrm{P}=0.010)$. In the $600-\mathrm{mg}$ subgroup, the mean decrease in the plasma concentration of viral RNA was $0.81 \log$ (95 percent confidence interval, 0.40 to 1.22 ).

Similarly, there were initial increases from base line in median CD4+ lymphocyte counts in all the ritonavir subgroups. In the 300-mg and the 400-mg subgroups, the median count had returned almost to the base-line value after 24 weeks of treatment. The 600-mg subgroup had the largest and most sustained increase in the median $\mathrm{CD} 4+$ lymphocyte count at 32 weeks of treatment - an increase from base line of 230 cells per cubic millimeter, measured in seven patients. This increase differed significantly from the increase in the 500-mg subgroup $(\mathrm{P}=0.030)$.

At two participating centers, viral RNA concentrations were also assessed with a more sensitive, quantitative PCR assay among 17 consecutive patients in the two subgroups receiving the highest dosages. Figure 3 shows the mean $( \pm \mathrm{SD})$ values obtained by this method. The mean maximal decrease, reached at week 8, was $1.94 \log$ (95 percent confidence interval, 1.37 to 2.51$)$. Clearly, the maximal decrease in the vi- 
Table 2. Mean $( \pm S D)$ Pharmacokinetic Measures Obtained after Three Weeks of Treatment with Ritonavir.

\begin{tabular}{lcccc}
\hline \hline MeasurE* & & Ritonavir Dose EVERy $12 \mathrm{HR}$ & \\
& $300 \mathrm{mg}$ & $400 \mathrm{mg}$ & $500 \mathrm{mg}$ & $600 \mathrm{mg}$ \\
& $(\mathrm{N}=12)$ & $(\mathrm{N}=13)$ & $(\mathrm{N}=13)$ & $(\mathrm{N}=10)$ \\
Time to maximal concentration $(\mathrm{hr})$ & $2.2 \pm 1.1$ & $2.8 \pm 1.1$ & $3.3 \pm 1.8$ & $3.3 \pm 2.2$ \\
Maximal concentration $(\mu \mathrm{g} / \mathrm{ml})$ & $5.7 \pm 2.5$ & $7.1 \pm 2.7$ & $10.9 \pm 2.6$ & $11.2 \pm 3.6$ \\
Area under the curve $(\mu \mathrm{g} / \mathrm{hr} / \mathrm{ml}) \dagger$ & $29.7 \pm 14.6$ & $39.7 \pm 16.4$ & $58.5 \pm 18.5$ & $60.8 \pm 23.4$ \\
Degree of fluctuation $\dagger$ & $1.26 \pm 0.24$ & $1.09 \pm 0.36$ & $1.19 \pm 0.38$ & $1.14 \pm 0.36$ \\
Trough concentration $(\mu \mathrm{g} / \mathrm{ml})$ & $1.23 \pm 0.88$ & $1.90 \pm 1.09$ & $2.81 \pm 2.14$ & $3.03 \pm 2.13$ \\
Half-life of ritonavir $(\mathrm{hr})$ & 3.1 & 3.2 & 2.7 & 3.2 \\
Apparent clearance of ritonavir (liters/hr) & $10.0 \pm 3.9$ & $9.5 \pm 3.7$ & $7.7 \pm 2.4$ & $8.9 \pm 3.2$ \\
\hline
\end{tabular}

*All pharmacokinetic measures were calculated as specified in the Methods section.

$\dagger$ Refers to the curve formed by plotting the ritonavir concentration against time.

$\doteqdot$ In the area under the curve.

ral RNA concentration was underestimated by the branched-chain DNA assay.

\section{Adverse Events and Safety}

Most patients reported at least one adverse event: 85 to 100 percent of those treated with ritonavir during the four-week, placebo-controlled phase and 88, 94, 95, and 100 percent of those in the 300-mg, 400-mg, 500-mg, and $600-\mathrm{mg}$ subgroups, respectively, during the maintenance phase. The events considered to be related to treatment with the study drug were nausea, circumoral paresthesia, and elevated levels of hepatic enzymes. Among the 84 patients who entered the study, 8 withdrew prematurely from the study during the four-week, placebo-controlled phase, 4 of them for reasons that were considered to be related to treatment with ritonavir: 1 because of nausea, and 3 because of elevated concentrations of aspartate aminotransferase and alanine aminotransferase. Among the 76 patients who continued the study into the maintenance phase, 25 discontinued treatment before the completion of all 32 weeks. Six of these discontinuations were considered related to treatment: three due to nausea, and three due to elevated aminotransferase concentrations.

Concentrations of aspartate aminotransferase, alanine aminotransferase, cholesterol, and triglycerides increased significantly during week 1 in the subgroups receiving the two highest dosages of ritonavir, whereas in the placebo groups there were no such increases. The elevations in cholesterol and triglyceride concentrations persisted throughout the 32 weeks of the study: among all subgroups, there were increases from base line of 30 to 40 percent for cholesterol and of 200 to 300 percent for triglycerides. During the maintenance phase, there were only sporadic increases in aspartate aminotransferase and alanine aminotransferase. Mean concentrations of alkaline phosphatase and bilirubin did not change, nor did hemoglobin concentrations, white-cell counts, or platelet counts.

\section{Discussion}

Ritonavir has prompt and potent antiviral activity, accompanied by increases in the GD4+ lymphocyte count. When we used a sensitive, PCR-based assay, the mean maximal reduction in the plasma concentration of viral
RNA, observed after eight weeks of treatment in 17 consecutive patients in the subgroup receiving the highest dosage of ritonavir, was $1.94 \log$. This reduction is stronger than those reported for reverse transcriptase inhibitors and other protease inhibitors. ${ }^{5,9-12}$ Moreover, a clear relation was found between increasing dosages and the duration of the response. The dosage of $600 \mathrm{mg}$ of ritonavir every 12 hours was best in both the magnitude and the duration of response. After 32 weeks of treatment, the average decrease from base line in viral RNA concentrations attained with this regimen was $0.81 \mathrm{log}$, with a corresponding median increase from base line in the CD4+ lymphocyte count of 230 cells per cubic millimeter (Fig. 2).

There was a partial decrease in antiviral activity after 12 to 16 weeks of therapy with high dosages of ritonavir. Attenuation of the antiviral effect has been observed after 4 to 10 weeks with zidovudine ${ }^{13}$ or 3 -thiacytidine ${ }^{14}$ and after 12 weeks with both these agents in combination. ${ }^{15,16}$ In the case of another protease inhibitor, MK-639, loss of antiviral effect was associated with the development of resistant viral isolates. ${ }^{17}$ Strains of HIV-1 that are resistant to ritonavir have been detected during serial passages of virus in the presence of the drug. ${ }^{18}$ Some viral isolates obtained from patients in this study show genotypic changes, with the wild-type valine of codon 82 frequently mutating to alanine and phenylalanine. Mutations at codons $54(\mathrm{Ile} \rightarrow \mathrm{Val}), 71 \quad(\mathrm{Ala} \rightarrow \mathrm{Val})$, and $84(\mathrm{Ile} \rightarrow \mathrm{Val})$ have also been found. Sequential phenotypic analysis of HIV from patients with waning responses to their viral loads revealed the emergence of viral strains that had diminishing in vitro susceptibility to ritonavir. ${ }^{19,20}$ If the development of resistance is the main reason for the loss of antiviral efficacy, higher doses of ritonavir resulting in higher plasma concentrations of the drug were effective in postponing the onset of such resistance.

This study extends the understanding of the relation between viral load and the GD4+ lymphocyte count. Recently, high turnover of both viral RNA and CD4+ lymphocytes during asymptomatic HIV-1 infection has been reported. ${ }^{21,22}$ In our study, CD4+ lymphocyte counts and plasma concentrations of viral RNA remained at approximately the base-line values in the patients receiving placebo. In the patients receiving ritonavir, steep decreases in concentrations of viral RNA were clearly associated with steep increases in CD4+ lymphocyte counts. This finding provides further evidence that the loss of CD4+ lymphocytes in patients with HIV-1 infection is mediated through the direct effects of the virus on infected cells or through other processes stimulated by the presence of HIV-1. It is unlikely that ritonavir caused CD4+ lymphocyte counts in the peripheral blood to increase because of shifts from reservoirs in lymphoid tissue. Patients with persistent suppression of virus had lasting increases in GD4+ lymphocyte counts, whereas those 
who did not maintain reduced concentrations of viral RNA had concomitant losses of CD4+ lymphocytes despite constant exposure to ritonavir.

Adverse events, mainly nausea and circumoral paresthesia, occurred frequently but were tolerated by most patients, leading to the withdrawal of ritonavir in only four patients. Increases in aspartate aminotransferase and alanine aminotransferase concentrations that were considered to be drug-related were seen mainly during the first weeks of treatment and led to the withdrawal of another six patients. The dose-dependent increase in triglyceride concentrations, whose mechanism is unclear, was asymptomatic and not associated with evidence of pancreatitis. The maximal tolerated dosage of ritonavir

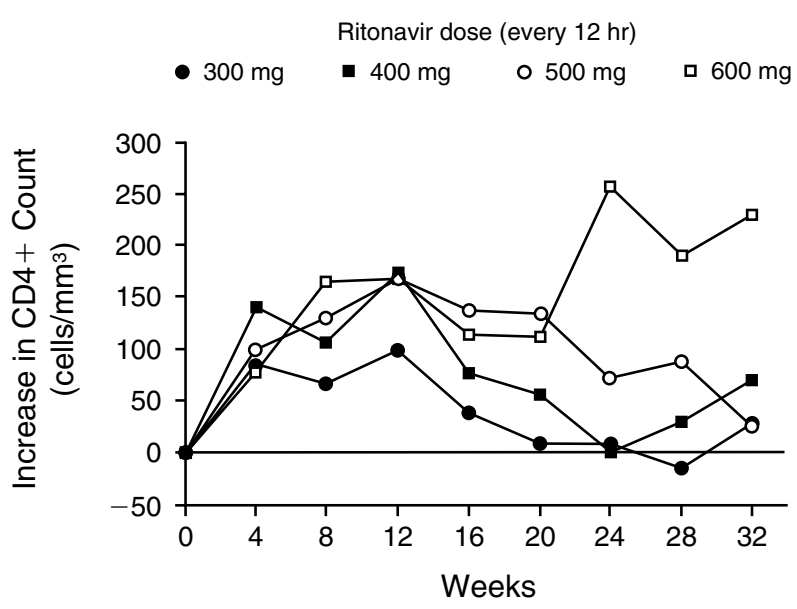

No. OF PATIENTS

$\begin{array}{lrrrrrrrr}300 \mathrm{mg} & 15 & 6 & 4 & 3 & 4 & 4 & 4 & 3 \\ 400 \mathrm{mg} & 17 & 9 & 7 & 7 & 6 & 5 & 6 & 4 \\ 500 \mathrm{mg} & 19 & 13 & 11 & 10 & 11 & 13 & 13 & 7 \\ 600 \mathrm{mg} & 16 & 15 & 14 & 13 & 12 & 10 & 9 & 7\end{array}$

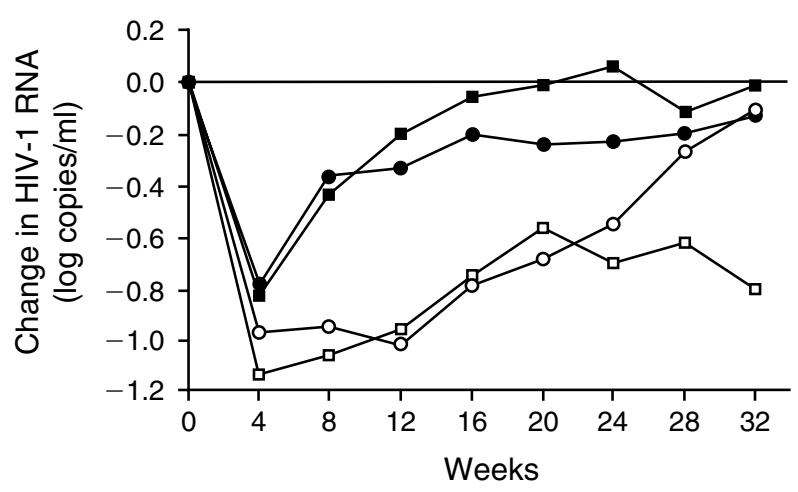

No. of PATIENTS

$\begin{array}{lrrrrrrrr}300 \mathrm{mg} & 15 & 7 & 5 & 5 & 4 & 5 & 5 & 4 \\ 400 \mathrm{mg} & 17 & 9 & 7 & 7 & 6 & 5 & 6 & 5 \\ 500 \mathrm{mg} & 18 & 12 & 9 & 10 & 11 & 12 & 13 & 8 \\ 600 \mathrm{mg} & 15 & 14 & 13 & 11 & 11 & 9 & 9 & 7\end{array}$

Figure 2. Changes from Base Line during the Maintenance Phase of Treatment, Lasting up to a Total of 32 Weeks, According to Dosage Subgroup.

Changes in median CD4+ lymphocyte counts (upper panel) and in mean concentrations of HIV-1 RNA as measured by the branched-DNA assay (lower panel) are shown. Some patients missed a measurement but returned for subsequent measurements.

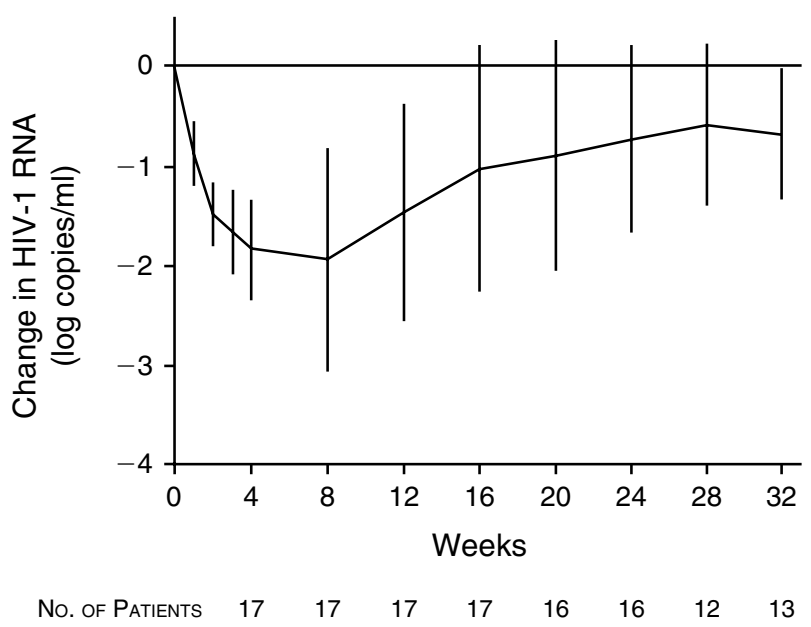

Figure 3. Changes from Base Line in the Mean ( \pm SD) Concentration of HIV-1 RNA as Measured by a More Sensitive PCR Assay in 17 Consecutive Patients in the Subgroups Receiving 500 $\mathrm{mg}$ and $600 \mathrm{mg}$ of Ritonavir Every 12 Hours during the Maintenance Phase, Lasting up to 32 Weeks.

Some patients missed a measurement but returned for subsequent measurements.

was not determined, although the appearance of nausea and of elevations in hepatic aminotransferase concentrations suggests that the dosage of $600 \mathrm{mg}$ every 12 hours approaches the maximum.

Pharmacokinetic considerations had a prominent role in this study. A low in vitro concentration of ritonavir (approximately $0.10 \mu \mathrm{M}$ ) was found to be 90 percent effective against HIV-1 type IIIB in MT4 cells in a conventional growth medium containing 10 percent fetal-calf serum. ${ }^{6}$ Ritonavir is 99 percent bound to plasma proteins; therefore, the 90 percent effective concentration found in the absence of high serum protein levels may underestimate the drug concentrations required to exert a similar effect in vivo. Experiments with ritonavir showed a progressive increase in the 90 percent effective concentration when in vitro testing medium contained progressively higher levels of human serum. Protease inhibitors diffuse freely across the cell membrane, and therefore the concentration of free drug in plasma may reflect concentrations of the drug inside cells ${ }^{23}$ (and Norbeck DW: personal communication). The functional 90 percent effective concentration, after adjustment for binding to protein, appeared to be about $3 \mu \mathrm{M}$ (approximately $2.1 \mu \mathrm{g}$ per milliliter). The dosages in our study were selected to yield drug concentrations above this value. The targeted effective concentration was reached, and all four dosage subgroups had initially substantial reductions in the viral load. However, longer-lasting effects on CD4+ lymphocytes and viral RNA were observed only in the dosage subgroups in which the mean trough concentrations of ritonavir exceeded the 90 percent effective concentration.

These early results with ritonavir monotherapy show potent antiviral and immunostimulatory effects. The precise clinical benefit conferred by ritonavir remains to be established. The possibility of extending the reductions in viral RNA achieved with ritonavir mono- 
therapy requires further study in which this agent is used in combination with reverse-transcriptase inhibitors and other protease inhibitors.

We are indebted to Judy Smith, R.N., for constant support in coordinating the study; to John Sninsky (Roche Molecular Systems, Alameda, Calif.) for providing the prototype of the PCR assay for HIV RNA; to Joep M.A. Lange, M.D. (National AIDS Therapy Evaluation Center, the Netherlands), for constructive comments; to Rich Hippensteel, M.S., and Scott Madarik, M.S., for statistical support; to Jill R. Burke and Philip Cunningham, B.Sc., for technical support; and to the patients who participated in the study.

\section{APPENDIX}

In addition to the study authors, the European-Australian Collaborative Ritonavir Study Group included the following persons: Hospital Clinico de Valencia - C. Gimeno; Hospital Germans Trias i Pujol - B. Clotet and J. Tor; Hospital de Bellvitge "Principes de España" — E. Ferrer; Hospital La Paz — P.L. Martinez; Hospital General Gregorio Marañon - S. Moreno and G. Zancada; Hospital 12 de Octubre - J. Alcami, A.R. Noriega, and F. Pulido; and Abbott Laboratories - H.N. Glassman.

\section{REFERENCES}

1. Richman DD. Resistance of clinical isolates of human immunodeficiency virus to antiretroviral agents. Antimicrob Agents Chemother 1993;37:120713.

2. Kohl NE, Emini EA, Schleif WA, et al. Active human immunodeficiency virus protease is required for viral infectivity. Proc Natl Acad Sci U S A 1988; 85:4686-90.

3. Debouck C. The HIV-1 protease as a therapeutic target for AIDS. AIDS Res Hum Retroviruses 1992;8:153-64.

4. Reedijk M, Boucher CAB, van Bommel T, et al. The safety, pharmacokinetics, and antiviral activity of $\mathrm{A} 77003$, a $\mathrm{C}_{2}$ symmetry-based human immunodeficiency virus protease inhibitor. Antimicrob Agents Chemother 1995:39:1559-64.

5. Kitchen VS, Skinner C, Ariyoshi K, et al. Safety and activity of saquinavir in HIV infection. Lancet 1995;345:952-5.

6. Kempf DJ, Marsh KC, Denissen JF, et al. ABT-538 is a potent inhibitor of human immunodeficiency virus protease and has high oral bioavailability in humans. Proc Natl Acad Sci U S A 1995;92:2484-8.

7. Pachl C, Todd JA, Kern DG, et al. Rapid and precise quantification of HIV1 RNA in plasma using a branched DNA signal amplification assay. J Acquir Immune Defic Syndr Hum Retroviral 1995;8:446-54.

8. Mulder J, McKinney N, Christopherson C, Sninsky J, Greenfield L, Kwok S. Rapid and simple PCR assay for quantification of human immunodeficiency virus type 1 RNA in plasma: application to acute retroviral infection. J Clin Microbiol 1994;32:292-300.
9. Katzenstein DA, Winters M, Bubp J, Israelski D, Winger E, Merigan TC. Quantitation of human immunodeficiency virus by culture and polymerase chain reaction in response to didanosine after long-term therapy with zidovudine. J Infect Dis 1994;169:416-9.

10. Jurriaans S, Weverling GJ, Goudsmit J, et al. Distinct changes in HIV type 1 RNA versus p24 antigen levels in serum during short-term zidovudine therapy in asymptomatic individuals with and without progression to AIDS. AIDS Res Hum Retroviruses 1995;11:473-9.

11. Havlir D, Cheeseman SH, McLaughlin M, et al. High-dose nevirapine: safety, pharmacokinetics, and antiviral effect in patients with human immunodeficiency virus infection. J Infect Dis 1995;171:537-45.

12. D'Aquila RT, Johnson VA, Welles SL, et al. Zidovudine resistance and HIV1 disease progression during antiretroviral therapy. Ann Intern Med 1995; 122:401-8.

13. Loveday C, Kaye S, Tenant-Flowers M, et al. HIV-1 RNA serum-load and resistant viral genotypes during early zidovudine therapy. Lancet 1995;345: 820-4.

14. Schuurman R, Nijhuis M, van Leeuwen R, et al. Rapid changes in human immunodeficiency virus type 1 RNA load and appearance of drug-resistant virus populations in persons treated with lamivudine. J Infect Dis 1995;171:1411-9.

15. Katlama C, European Lamivudine HIV Working Group. Combination 3TC/ZDV vs. ZDV monotherapy in ZDV naive HIV-1 positive patients with a CD4 of 100-400 cells $/ \mathrm{mm}^{3}$. In: Program and abstracts of the Second National Conference on Human Retroviruses and Related Infections, Washington, D.C., January 29-February 2, 1995. Washington, D.C.: American Society of Microbiology, 1995:29. abstract.

16. Staszewski S, European Lamivudine HIV Working Group. Combination 3TC/ZDV vs. ZDV monotherapy in ZDV experienced HIV-1 positive patients with a CD4 of 100-400 cells $/ \mathrm{mm}^{3}$. In: Program and abstracts of the Second National Conference on Human Retroviruses and Related Infections, Washington, D.C., January 29-February 2, 1995. Washington, D.C.: American Society of Microbiology, 1995:29. abstract.

17. Condra JH, Schleif WA, Blahy OM, et al. In vivo emergence of HIV-1 variants resistant to multiple protease inhibitors. Nature 1995;374:569-71.

18. Markowitz M, Mo HM, Kempf DJ, et al. Selection and analysis of human immunodeficiency virus type 1 variants with increased resistance to ABT538, a novel protease inhibitor. J Virol 1995;69:701-6.

19. Molla A, Bouche C, Korneyeva M, et al. Evolution of resistance to the protease inhibitor ritonavir (ABT-538) in HIV infected patients. Presented at the Fourth International Workshop on HIV Drug Resistance, Sardinia, Italy, July 6-9, 1995:69. abstract.

20. Norbeck D, Hsu A, Granneman R, et al. Virologic and immunologic response to ritonavir (ABT-538), an inhibitor of HIV protease. Presented at the Fourth International Workshop on HIV Drug Resistance, Sardinia, Italy, July 6-9, 1995:70. abstract.

21. Wei X, Ghosh SK, Taylor ME, et al. Viral dynamics in human immunodeficiency virus type 1 infection. Nature 1995;373:117-22.

22. Ho DD, Neumann AU, Perelson AS, Chen W, Leonard JM, Markowitz M. Rapid turnover of plasma virions and CD4 lymphocytes in HIV-1 infection. Nature 1995;373:123-6.

23. Bilello JA, Bilello PA, Stellrecht K, et al. The uptake and anti-HIV activity of A-80987, an inhibitor of the HIV-1 protease, is reduced by human serum $\alpha_{1}$-acid glycoprotein. J Clin Invest (in press).

\section{Massachusetts Medical Society \\ Registry on Continuing Medical Education}

To obtain information on continuing medical education courses in the New England area, call between 9:00 a.m. and 12:00 noon, Monday through Friday, (617) 893-4610 or in Massachusetts 1-800-322-2303, ext. 1342. 